\title{
A Knowledge Representation Model for Formalizing Subcontractors' Scheduling Process
}

\author{
Jaehyun Choi
}

Assistant Professor, School of Architectural Engineering, Korea University of Technology and Education, Korea

\begin{abstract}
Construction project participants that comprise the construction supply chain are increasingly making use of information technology (IT) to manage their businesses. Among various applications of IT to the construction industry, the construction scheduling technique has progressed drastically as scheduling software has become commercially available to project participants. However, the limitation of applying IT to construction scheduling still exists due to the fact that the schedule developed mostly by a general contractor (GC) or a construction management firm (CM) tends not to take the subcontractors' schedule information into consideration. The objective of this research was to formalize subcontractors' planning and scheduling processes through the development of a knowledge representation model (KRM). The KRM represented the definitions of concepts and the relationships between concepts in the construction scheduling domain. In order to formalize the construction scheduling process from the subcontractor's standpoint, an inductive approach was used. Even though the subcontractor's scheduling process varied, the KRM provided in-depth insight into the scheduling process. Various subcontractors' scheduling processes could be retrieved by conducting comparative analysis with the KRM developed by this research.
\end{abstract}

Keywords: IT application; construction scheduling; knowledge representation; subcontractors' scheduling; inductive approach

\section{Introduction}

Construction project participants that comprise the construction supply chain are increasingly making use of information technology (IT) to manage their businesses. IT application in the construction industry is divided into many different categories because it varies according to the construction operation processes and the construction firms (Froese 2010). Among various usages of IT, the construction scheduling technique has progressed drastically as scheduling software has become commercially available to the project participants. These software products allow the project participants to manage multiple projects simultaneously by effectively allocating their resources to multiple projects.

However, the limitation of applying IT to construction scheduling still exists due to the fact that a schedule developed mostly by a general contractor (GC) or a construction management firm (CM) tends not to take the subcontractors' schedule information into consideration; in current practice the $\mathrm{GC}$ or $\mathrm{CM}$

*Contact Author: Jaehyun Choi, Assistant Professor,

School of Architectural Engineering, Korea University of Technology and Education, 307 Byungcheon, Chonan, Chungnam, 330-708 Korea

Tel: +82-41-560-1336 Fax: +82-41-560-1224

E-mail: jay.choi@kut.ac.kr

(Received October 4, 2011 ; accepted July 24, 2012) decides the construction schedule with little reflection on the subcontractors' scheduling information, even though information sharing between the GC/ $\mathrm{CM}$ and each subcontractor is important to improve coordination in the construction schedule. Previous research showed that formalizing subcontractors' scheduling processes could provide the opportunity for better project schedule coordination (Froese 1998). However, little research has performed in-depth analysis of the subcontractors' scheduling process. It was pointed out that the different usage of computer hardware and software applications among firms has limited information sharing (El-Mashaleh et al. 2006). These applications represent data in different ways and users tend to use various terminologies for the same or similar concepts (O'Brien et al. 2003). The heterogeneity is also a result of the different scopes of different business rules, the level of detail in project management, and so on. It was also recognized that uniform adoption of standards by many firms in any given project supply chain is unlikely.

The objective of this research was to formalize subcontractors' planning and scheduling processes through the use of a knowledge representation and process mapping technique. This research focused on the formalization of the scheduling process rather than underlying terminology. Due to the variable representation of the same or similar concepts, formalizing the terminology and its representation 
underlying the planning and scheduling process of subcontractors becomes less important than the process for developing a project schedule.

\section{Research Methodology}

Accomplishing the formalization of the scheduling process requires investigating knowledge about the various ways scheduling data is semantically represented in legacy systems. A case study was conducted and its findings were presented by way of a formal representation.

It was a highly challenging task to formalize the scheduling process because the process can vary according to the contract (delivery method), the detailed level (general contractor, subcontractor, and supplier), and the business scope (mechanical, electrical, roofing, etc.). It was also hard to access subcontractors' information systems and identify the factors affecting scheduling (resources, materials, costs, etc.) due to confidentiality issues.

As a protocol of the case study, a structured interview was conducted with a roofing company. The structured interview included general information about business operations as well as scheduling processes such as:

1. Required information between the $\mathrm{GC} / \mathrm{CM}$ and Subcontractors;

2. Formalization of subcontractors' information usage for the scheduling process and semantics;

3. Data representation and semantic variances;

4. Sample data acquisition.

After representing the structure of legacy sources (Subcontractors), the hierarchical structure of the data structure was disclosed. Finally, these data were translated into an effective formation.

\subsection{Knowledge Representation Model (KRM)}

An inductive approach was employed to develop a knowledge representation model (KRM) for the construction scheduling process. In the inductive approach, the model can be built by analyzing a specific case of the subcontractor's processes and representation (Gruninger 2002). Given the information collected and analyzed, the general format of the KRM was developed in order to embrace multiple cases. In order to model the construction scheduling process and method, the IDEFO process and AEC core modeling techniques were employed (Hegazy 2001).

Protégé 2002 was used to develop the KRM. Even though the design components of Protégé 2002 are similar to the relational database model in that both use classes (entities) and slots (properties), Protégé 2002 centers more on the structure of classes and slots (properties) than the structure of domain knowledge (Noy 2002). The most significant factor of the KRM is that it considers the detailed level in terms of concept, extensibility, and maintainability. For the purpose of data retrieval, Protégé 2002 requires the explicit representation of definitions and the relations of the definitions for construction scheduling knowledge.

\subsection{Components of KRM}

The components of the KRM in Protégé 2002 include classes, slots, and instances. For the distinct definitions, the names of classes and the first letter of slot names were capitalized, and the names of instances were written with quotation marks.

A class is a basic component of the model describing concepts in the domain. By defining the subclasses within a class, a hierarchical structure can be established. Designing classes and their subclasses depends on the desired detailed level. The relation between a subclass and its super-class is described as "is a" or "kind of".

A property of a class is called a slot. It defines the internal structure of concepts since a class itself does not contain knowledge. For example, if ACTIVITY is designed as a class, the property of the activity, such as Start-date, End-date, and Cost, can be the slot of the class. Thus it is required to define which class a slot describes.

In the class hierarchy, the slots in the super-classes are inherited by the subclasses. If a PROJECT class has WORK ITEM as a subclass, the slots of PROJECT, such as Number and Description, are inherited by WORK ITEM. Subclasses can be built into a class when additional knowledge is required because a subclass may have more slots than its super-class.

The other important role of the slot is that it defines the relations among classes. For example, ACTIVITY (subclass of the PROJECT class) uses INPUT to produce the OUTPUT. The relation between ACTIVITY and INPUT is Use and Is-used-by. If the Use slot is built under ACTIVITY, ACTIVITY is defined as a domain of the Use slot and the INPUT class is defined as a range of the slot. The slot value is called instance. Each class has a direct instance, for example, ACTIVITY has specific "activities" as a direct instance and then, those activities have slots that need to be input. The inputting of data into slots composes knowledge as an instance.

\section{Construction of KRM}

The roofing subcontractor's scheduling process obtained from the company's information system was analyzed to provide generic insight into the subcontractor's construction scheduling process. In order to provide the list of concepts in the domain of construction scheduling, a high-level class model was developed based on both realistic data obtained from the roofing contractor and domain knowledge of the scheduling. The realistic data included an operation process such as estimating, bidding, and scheduling. These three tasks represent the major order of operations since most subcontractors perform estimating in order to come up with a bid price and 
then participate in the bid, and perform scheduling for the project that they have won. The domain knowledge of scheduling indicates the general principles represented by construction domain concepts, which compensates the realistic data.

\subsection{Building a High-level Process Model}

The high-level process model was developed to illustrate the overall structure of the classes that compose the KRM. There are four super-classes of INPUT, CONTROL, PROCESS, and OUTPUT. Each super-class has its subclasses to represent the hierarchical structure of the KRM as shown in Fig.1.

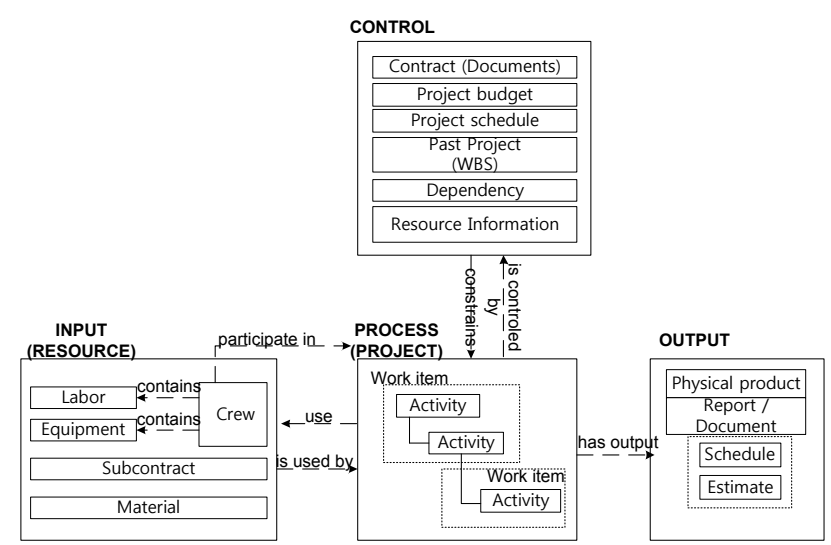

Fig.1. High Level Process Model

The RESOURCE class substitutes the INPUT class. The INPUT class has subclasses of CREW, MATERIAL, and SUBCONTRACTOR. Among the subclasses of the RESOURCE class, CREW is composed of LABOR and EQUIPMENT and is related to PROCESS by the "Participate-in" relationship, as CREW operates PROCESS. The other reason for building the subclasses of the CREW class is that they have additional information about productivity rates, which decide Activity-durations.

The PROCESS class contains subclasses of WORK ITEM and ACTIVITY. It reflects the hierarchical structure of project breakdown and the reality of the scheduling process. PROJECT replaces PROCESS to model the construction project scheduling. PROJECT uses RESOURCE and RESOURCE is used by PROJECT.

The CONTROL class was created with subclasses of CONTRACT, HISTORICAL DATA, DEPENDENCY, and RESOURCE INFORMATION. The CONTRACT class is represented by contract documents, and its subclasses are PROJECT BUDGET, PROJECT SCHEDULE, and BID ITEM LIST. The PROJECT BUDGET represents the bidding price for a specific project. The PROJECT SCHEDULE is required for the subcontractor to submit to the general contractor.

The CONTROL constrains PROJECT, the subclasses of WORK ITEM, and ACTIVITY. It is important to note that the CONTROL class only acts at each step of the scheduling process, rather than constraining the PROJECT class or its subclasses. The CONTROL class is disjointed in that it does not have common instances and changes at each step of the scenario. The CONTROL class identifies the association of the CONTROL class with the PROJECT class and its subclasses for the purpose of demonstrating how decisions are made.

The OUTPUT for construction scheduling is comprised of reports and documents containing schedule and cost. The output can be a PHYSICAL OBJECT, which is one of the subclasses of OUTPUT. Fig.2. shows a screenshot of Protégé 2002 to illustrate the hierarchical structure of classes.

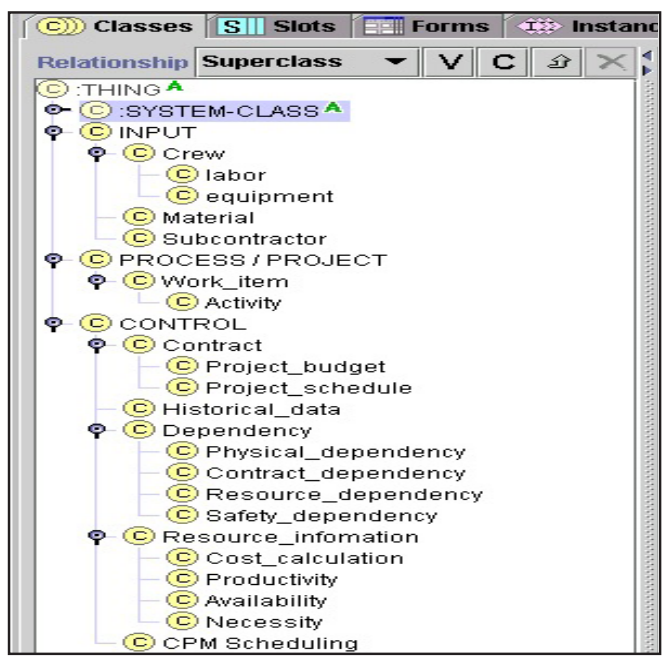

Fig.2. Class Hierarchy of KRM Developed by Protégé 2002

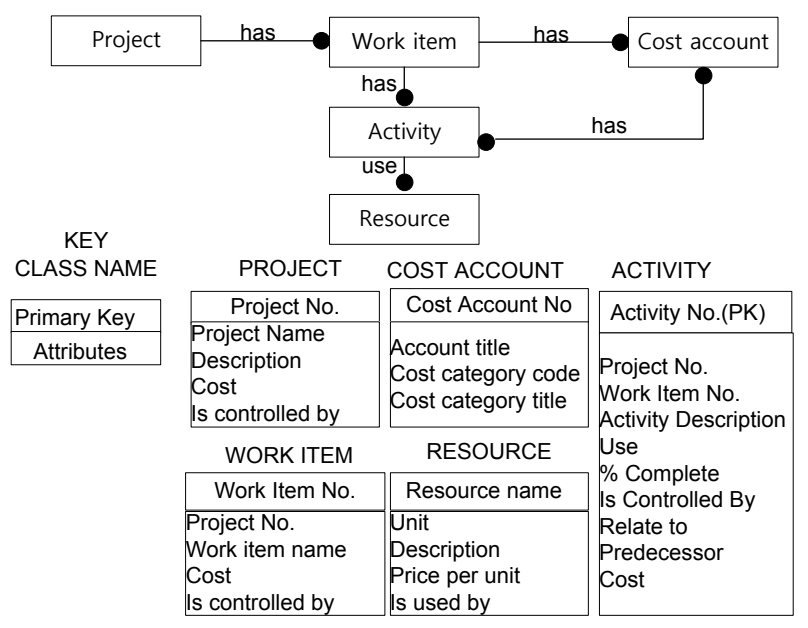

Fig.3. Scheduling Database Structure

\section{Schedule Development Process}

The scheduling process was represented by utilizing the class definitions. Firstly, the subcontractor's construction schedule development process was verified in conjunction with the general scheduling concepts. Since the subcontractor's operation rules for the resource input process are an important part of the process, the data source and location within the company system were identified at each step of the scheduling process by identifying the control class. 
After developing the subcontractor's scheduling scenario, a rescheduling scenario was generated to test subcontractors' scheduling processes and to exemplify the scenario. Even though the actual scheduling process may be slightly different from one project to another, the scenario made generalizations of the scheduling process for a single firm.

Fig.4. shows the overall scheduling process throughout the whole process. Before bidding, conceptual scheduling and estimating were done and submitted as part of the bid documents. The detailed scheduling process after a successful bid is illustrated inside the box.

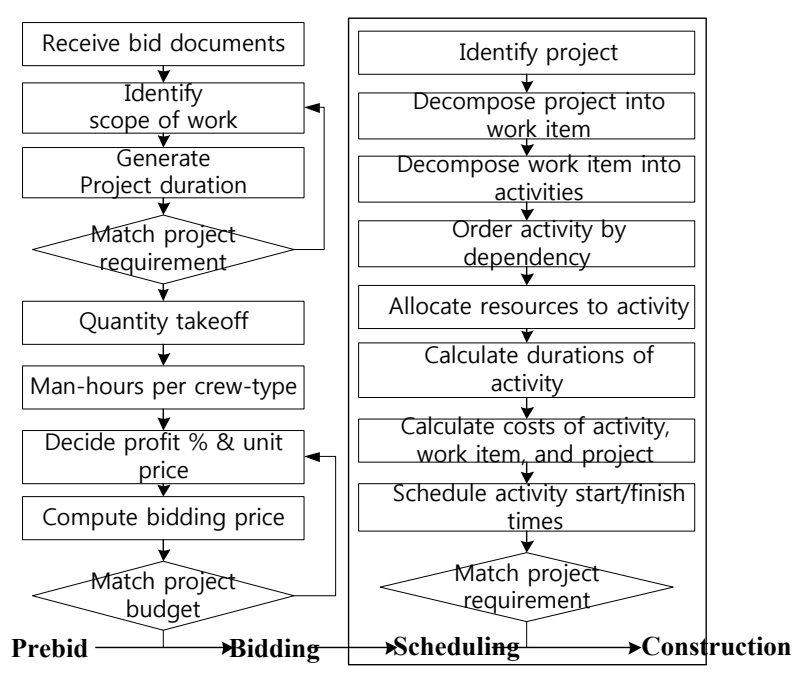

Fig.4. Process Model

\subsection{Scheduling Scenario}

At every step of the scenario the researcher defined what the input class was, how the controls affect the class, and where the output class was stored. Three projects were in progress at the time of investigation. Fig.5. shows the overall structure of research data provided. From the three projects, project 2 was selected to exemplify the scheduling scenario.

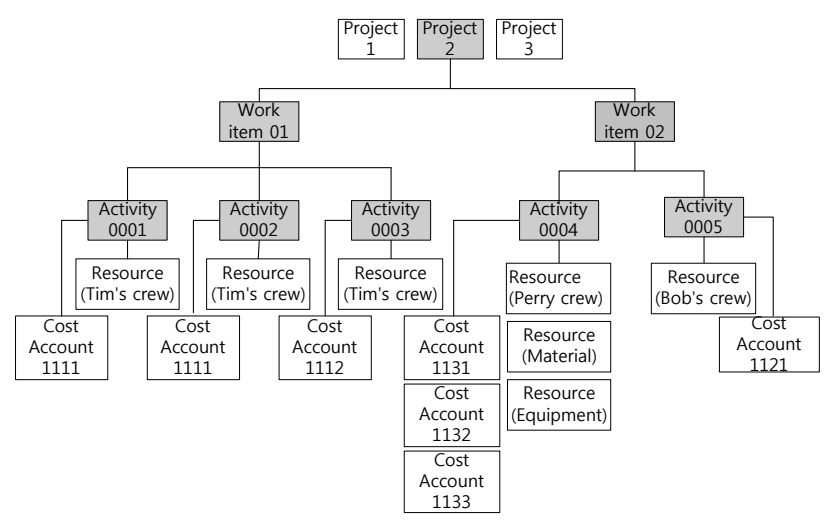

Fig.5. Overall Structure of Sample Data

\subsubsection{Identify project}

A "project" is identified from the PROJECT class and classified by such slots as Project-number, Name,
Description, Cost, and Is-controlled-by. "Project 2" was chosen as an instance. "Project 2" was for re-roofing the Weil Hall building located inside of the University of Florida campus, as shown in Table 1.

Table 1. Research Data for Project Class

\begin{tabular}{ll}
\hline Class & Slot \\
\hline Project No. & 2 \\
Name & Weil Hall \\
Description & Re-roof \\
Project cost & $\begin{array}{l}\$ 114,380 \\
\text { Is controlled by }\end{array}$ \\
& $\begin{array}{l}\text { Scope of work from Contract documents } \\
\text { (Bid package, plans and specifications, etc.) }\end{array}$ \\
\hline
\end{tabular}

\subsubsection{Decompose project into work item}

After identifying a "project" from the PROJECT class, the class was decomposed into the instances of "work items" (Table 2.). In the research data, "project $2 "$ is decomposed into two work items of "demolition of existing roof (01)" and "installing new roof (02)". The relationship between PROJECT and WORK ITEM is one-to-many.

When decomposing a "project" into "work items", the input data was the "project" instance with Number, Name, and Description slots. Then, CONTRACT DOCUMENTS such as bid packages and plans and specifications obtained from the $\mathrm{GC} / \mathrm{CM}$ controlled the process, since from the documents a subcontractor verifies the scope of work.

Table 2. Research Data for Work Item Class

\begin{tabular}{ll}
\hline Class & Slot \\
\hline Work item No. & 01 \\
Project No. & 2 \\
Work item name & Demolition of existing roof \\
Work item cost & $\$ 6,760$ \\
Is controlled by & Historical data \\
Work item No. & 02 \\
Project No. & 2 \\
Work item name & Installation of new roof \\
Work item cost & \$107,620 \\
Is controlled by & Historical data \\
& Physical dependency \\
\hline
\end{tabular}

\subsubsection{Decompose work item into activity}

A "work item" is broken down into "activities" that can be understood and controlled by such project personnel as project manager, project engineer, and superintendent. To simplify the process, the first work item was "01. Demolition of existing roof", had the three activities of "1001-Demolish roof insulation", "1002-Demolish sheet metals", and "1003-Finishing demolition". Only activity 1001 is shown in Table 3. for illustration purposes. The number of "activities" was dependent upon a scheduler's timely decision.

Historical data provided the basis to decide the relevant "activities" for the specific "work item". Hence, in the example work item (Table 2.), "work item 01 " is controlled by HISTORICAL DATA. When having multiple work items, however, the DEPENDENCY class and its subclasses could also be applied to the WORK ITEM class as a CONTROL class. For instance, "work item 02" needed to wait until 
"work item 01" was finished since demolition should be done before installing the new roof. "Work item 02" was controlled by physical dependency based on the feature of the "work item".

Table 3. Sample Data for Activity Class

\begin{tabular}{ll}
\hline Class & Slot \\
\hline Activity No. & 1001 \\
Project No. & 2 \\
Work item No. & 1 \\
Activity description & Demolish roof insulation \\
Early start date & Jan 4, 2002 \\
Early finish date & Jan 11, 2002 \\
Late start date & Jan 9, 2002 \\
Late finish date & Jan 16, 2002 \\
Planned start date & Jan 7, 2002 \\
Planned finish date & Jan 14, 2002 \\
Duration & 6 \\
Predecessor & None \\
Successor & 0002 \\
Relate to predecessor & N/A \\
\% Complete & N/A \\
Cost account No. & 1111 \\
Use & Tim's crew \\
Is controlled by & Contract dependency \\
Activity cost & \$3,120 \\
\hline
\end{tabular}

\subsubsection{Order activities by relationship}

Once "activities" were developed for a particular project, the DEPENDENCY class controlled the steps for ordering the activity. The DEPENDENCY class was comprised of PHYSICAL DEPENDENCY, RESOURCE DEP E N D N C Y, S A F E T Y DEPENDENCY, and CONTRACT DEPENDENCY.

In Table 3., "activity 1001 ", was controlled by CONTRACT DEPENDENCY as an initial activity where "activity 1001" was required by the contract to be started no later than Jan 9, 2002. "Activity 1002" was controlled by PHYSICAL DEPENDENCY because it could not be started until "activity 1001" was finished. Since "activity 1001" was considered a predecessor of "activity 1002", these two activities were related by FS.

As "activity 1001", "activity 1002", and "activity 1003 " shared the resources of "Tim's crew", "activity 1002" and "activity 1003" were also controlled by RESOURCE DEPENDENCY in that those three activities could not be overlapped due to resource conflict.

\subsubsection{Allocate resource to activity}

Once "activities" are ordered based on DEPENDENCIES, "resources" are allocated to activities. The control factors while allocating resources were as follows:

- Which resources are needed for each activity? (Resource-name)

- How many resources are needed for each activity? (Unit)

- How long will the activity take? (Unit and Productivity-rate)

- How much is the activity cost going to be? (Priceper-unit)

- Are those resources available during the scheduled time? (Resource-availability)
If an "activity" needs the "resources" of one superintendent, two laborers, and a crane, the "activity" selects three Resource-names as shown in Table 4. After identifying RESOURCE NECESSITY for an "activity", RESOURCE AVAILABILITY should be considered since some "activities" cannot be scheduled during the same time period due to insufficient available resources. In order to find out RESOURCE AVAILABILITY, it is very important to recognize when each resource is scheduled. Therefore, the RESOURCE class should contain information on which activities are scheduled to use the "resources".

Finding RESOURCE AVAILABILITY is a straightforward task. The KRM examines the "Isused-by" slot in "resource" instances. If the resource of "Tim's crew" was allocated to the "activity 1001", "activity 1002", and "activity 1003", the working dates of "Tim's crew" can be obtained from the Plannedstart-date and Planned-finish-date slots from those three "activity" instances.

\begin{tabular}{|c|c|c|c|}
\hline $\begin{array}{l}\text { Name } \\
\text { (user defined) }\end{array}$ & Unit & Description & $\begin{array}{l}\text { Price per } \\
\text { Unit }\end{array}$ \\
\hline Equipment & Each & Crane & $\$ 1,200$ \\
\hline Superintendent & Hours & $\begin{array}{l}\text { Superintendent - } \\
\text { Installation }\end{array}$ & $\$ 25$ \\
\hline Laborer 1 & Hours & Labor- Installation & $\$ 20$ \\
\hline Laborer 2 & Hours & Labor- Installation & $\$ 20$ \\
\hline Laborer 3 & Hours & Labor- Installation & $\$ 20$ \\
\hline
\end{tabular}

\subsubsection{Calculate activity duration}

Activity-duration is determined by dividing the work units by the Productivity-rate of each CREW (LABOR and EQUIPMENT). In general, a company's HISTORICAL DATA from past projects may indicate the Productivity-rate of each "crew". Internal documents such as a daily diary are also a good source for retrieving the Productivity-rate.

In the case of not having information about the Productivity-rate but having the Activity-cost, some calculation can be applied. For example, if the budgeted cost amount and quantity of an "activity" are known, the Duration of that "activity" can be calculated as follows:

- Quantity of roof installation: 1000 square meter (SM)

- Budget amount: $\$ 8,000$

- Hourly cost: $\$ 215 / \mathrm{hr}$ from resource cost

- Cost rate: $\$ 8,000 / 1000 \mathrm{SM}=\$ 8 / \mathrm{SM}$

- Production rate: Cost rate/Hourly rate $=(\$ 8 / \mathrm{SM}) /$ $(\$ 215 / \mathrm{hr})=0.037 \mathrm{hr} / \mathrm{SM}$

- Total installation time: $0.037 \mathrm{hr} / \mathrm{SM} \times 1000 \mathrm{SM}=$ $37 \mathrm{hrs}=5$ days

Therefore, this "activity" should be done in 5 days in order to meet the budget cost.

4.1.7 Calculate activity/work item/project costs and cost account

Activity-cost is calculated after allocating resources and calculating activity duration. From the research data of "activity 1001 " in "project 2" (Table 4.) 
information could be easily retrieved. The resource "Tim's crew" was used for six days and the cost of "Tim's crew" was $\$ 65$ per hour. Hence the Activitycost of "activity 1001 " will be $\$ 3,120$ ( $8 \mathrm{hrs} /$ day $\times 6$ days $\times \$ 65.00=\$ 3,120.00)$.

The Work-item-cost is a simple adding-up of Activity-costs. If "work item 01" has the three activities of "activity 1001 ", "activity 1002", and "activity 1003", and the cost of each is $\$ 3,120.00$, $\$ 2,080.00$, and $\$ 1,560.00$, the cost of "work item $01 "$ will be,

- Cost of "work item 01": \$3,120.00+\$2,080.00+ $\$ 1,560.00=\$ 6,760.00$

- Cost of Project 2: $\$ 6,760.00$ ("Work item 01") + $\$ 7,620.00$ ("Work item 02") $=\$ 114,380.00$

The cost Account and Activity have a many-tomany relationship. The activity cost can have several cost accounts. The cost account has a different numbering structure for each category and an activity uses multiple cost categories such as labor, material, equipment, and subcontractor. COST CALCULATION controls calculating the costs of "activity", "work item", and "project". The calculated costs are then input into the cost slot of each "project", "work item", and "activity" slot.

\subsubsection{Scheduling output}

After inputting the slot values, each activity's early/ late start and early/late finish date is calculated by using the critical path method (CPM). Fig.6. shows the scheduling output in the Primavera Project Planner (P3) in order to represent the CPM applied to the example of "project 2"

RESOURCE CONSTRAINTS should be checked to find out if there are resource conflicts among the "activities" in any given activity order. Conflicts may also occur as a result of the "activities" from other "projects". Fig.6. also shows the activity bar chart across multiple projects in progress after sorting activities by their resource usage. It is shown that there was no resource conflict in the given schedule.

If two different "activities" used the same limited "resource", the company logic would need to be applied to find the "activity" with priority. For example, the "activity" which has the earliest late start, the least total float, or the largest amount of resources, can be given priority. However, the priority of an activity depends on the timely decision of the company.

\subsection{Simplified Re-scheduling Scenario}

The objective of developing a re-scheduling scenario was to test the scheduling process developed in Protégé 2002 by utilizing the resource usage when accommodating schedule change. In order to explain the re-scheduling process, some assumptions were made.

Firstly, on the start day of "work item 1" of "project 2 ", there was a six-day time period during which no work item could be scheduled, as shown in Fig.7. The remaining four "Projects" had schedules that should

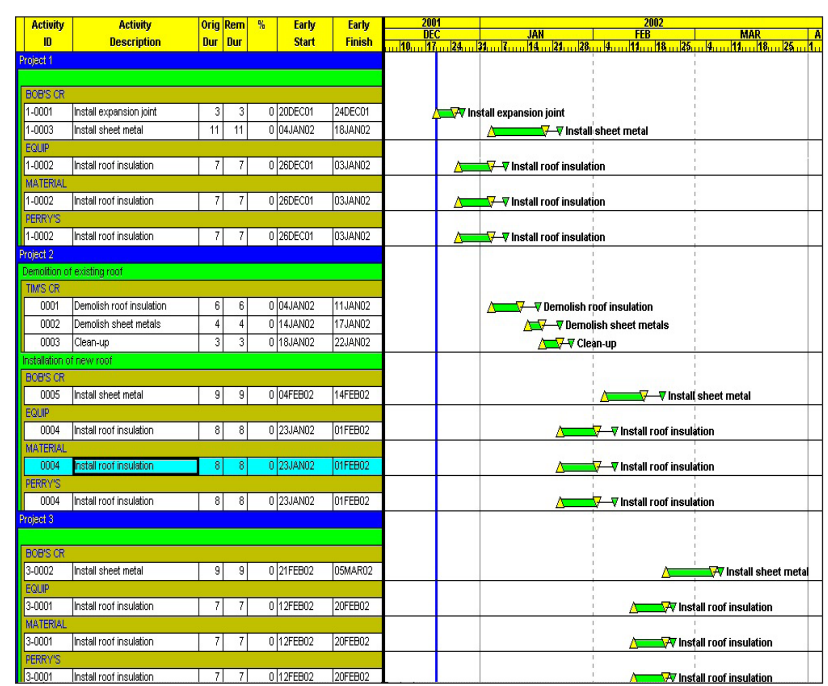

Fig.6. Project Overview by Resource Use

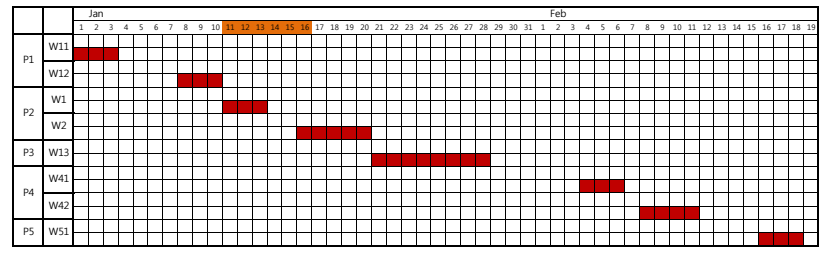

Fig.7. Re-scheduling Scenario

not be changed by the impact of rescheduling "Project $2 "$.

Second, all "work items" had only one "activity", utilizing the resource of "Tim's crew" as if "Tim's crew" was the only resource. As a consequence, no "activity" overlapping was allowed and the duration of activities represented the duration of the resource assigned. Each "work item" has a Finish-to-Start relationship. The rescheduling process for "Project 2" is illustrated in Fig.8. by data manipulation language.

\subsubsection{Retrieve projects}

The "Projects" in progress can be retrieved from the PROJECT class. In this scenario, there were five "projects".

SELECT: Project-number and Name slots

FROM: PROJECT class

WHERE: Project-No. $=1,2,3,4$, and 5

\subsubsection{Retrieve work items}

In order to find out the "work items" of the "projects", it is necessary to look into the WORK ITEM class related to the "projects". In the sample data provided, "project 2" had two work items ("work item 01 and $02 "$ "), and "work item 02" could be started only after "work item 01" was finished. This process was repeated until all the "work items" for the rest of the four "projects" were finished.

- SELECT: Work-item-number and Work item name slots

- FROM: WORK ITEM class

- WHERE: Project No. $=2$

\subsubsection{Retrieve activities}

All "work items" had only one "activity" in this 


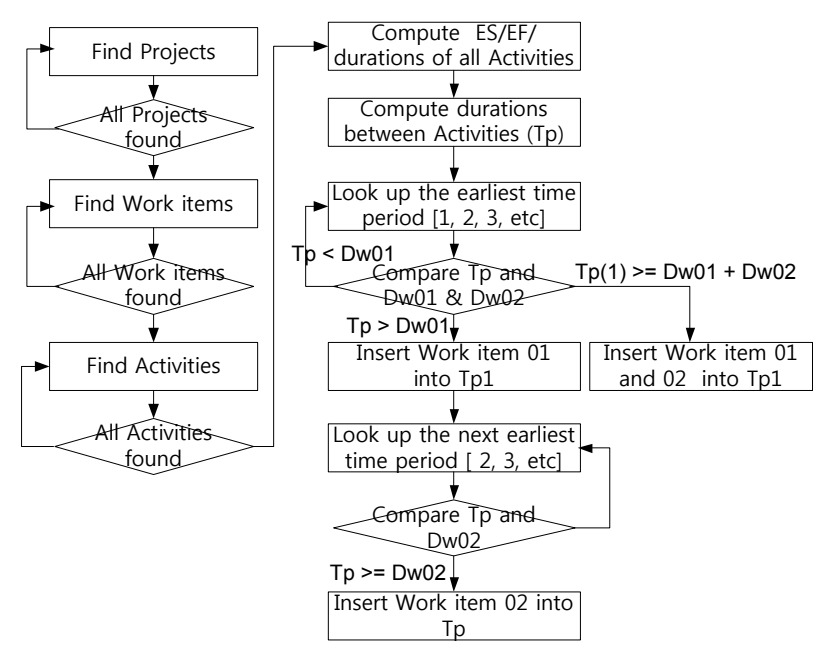

Fig.8. Scheduling Process Scenario

scenario (Activity 1002 and 1003 were eliminated for the rescheduling scenario). Thus, "Activities" were found easily in the same way as finding work items.

- SELECT: Activity-number and Description slots

- FROM: ACTIVITY class

- WHERE: Work item No. $=01$

This process was repeated until all "activities" for the rest of the "work items" in the other "projects" were found. Through the hierarchical structure of "project", "work item", and "activity", "activities" were mapped with the "project" they belong to.

- SELECT: ES, EF, and Duration

- FROM: ACTIVITY class

- WHERE: Activity No. $=1001$, Work item No. $=01$

By obtaining the start and end date of each activity, the duration of activities was simply calculated by subtracting the ES from the EF. After retrieving the start/end date of all "work items" ("Activities") and their Durations, the schedule showed the days scheduled for all "activities" by listing "work items" on a calendar.

To compute the duration between the activities (Time Period, TP) and the available time period the duration was identified.

- Find first "work item" scheduled (with start/end dates);

- Find second "work item";

- Compute Duration between these two items: Subtract the EF of the first "work item" from the ES of second "work item".

This process was repeated until all the time periods between work items were found. For the test scenario, "work item 01" and "work item 02" of "Project 2" had to be rescheduled. In order to find a place where "work item 01" and "work item 02" could be scheduled, the earliest time period existing between the earliest two work items was looked up. If that time period was long enough to place "work item 01" and "work item 02", that is, if the earliest time period was longer than the sum of "work item 01" and "work item 02", two work items could be scheduled. If the time period was longer than the duration of "work item 01" but shorter than the sum of the duration of "work item 01 " and "work item 02 ", only "work item 01 " could be scheduled. Then a second time period would have to be looked up to schedule "work item 02".

- Rescheduling: Look up the time period (Tp) from the earliest time duration.

- Definition of Tp: Duration between the earlier "work item" scheduled and the later "work item".

- Calculation

1. Tp1: ES of second "work item" - EF of first "work item"

2. Tp2: ES of third "work item"- EF of second Work item, etc.
a) If Tp1 $>=$ Sum of "work item 01" and "work item 02 ", then insert both items to Tp1.
b) If Tp1> "work item 01 ", then insert "work item $01 "$ to Tp1.
c) Go to $\mathrm{Tp} 2$.
d) If Tp2 $>=$ "work item 02", then insert "work item $02 "$ to $\mathrm{Tp} 2$.
e) Repeat until "work item 02" is placed.
f) If Tp1<"work item 01 ", then go to Tp2.
g) Follow Step a).

\section{Formal Representation of KRM}

The scheduling process model (Fig.9.) shows the overall KRM structure to describe the relationships between classes (slots) and CONTROL classes at each step of the scheduling process.

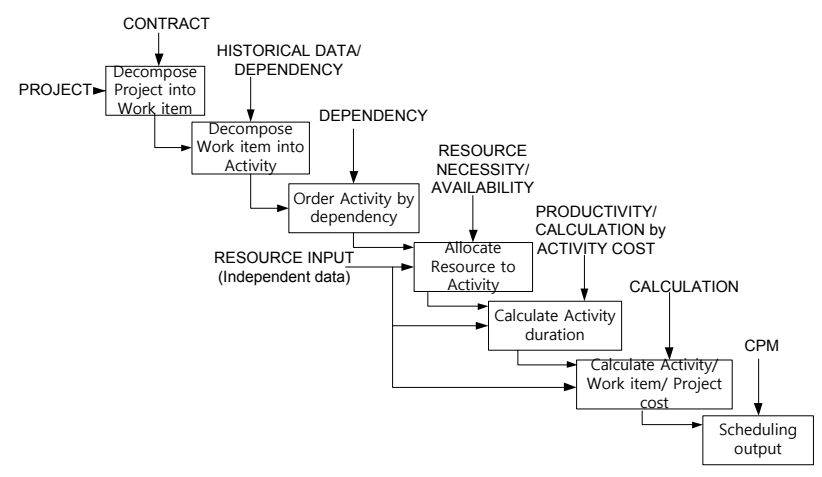

Fig.9. Scheduling Process Model

Since the INPUT and CONTROL classes may change in each scheduling process, a series of the IDEFO process model was adopted to represent sequences. In the model, the OUTPUT of each process was an INPUT to the next process.

Constrains and Is-part-of represented the hierarchical structure between PROJECT and WORK ITEM and WORK ITEM and ACTIVITY. When decomposing PROJECT into WORK ITEM and WORK ITEM into ACTIVITY in the scheduling process model, these two slots provided a tool to relate those classes.

Use and Is-used-by represented the relationship between the PROJECT class and RESOURCE class because the PROJECT class used the RESOURCE 
class and the RESOURCE class was used by the PROJECT class. When allocating "resources" to an "activity" in the scheduling process model, these two inverse slots were used to relate the ACTIVITY and RESOURCE classes.

Constrains and Is-controlled-by were defined as applicable restrictions that affected the performance of the project representing the relations between the PROJECT class and CONTROL class at each step of the scheduling process. Thus the CONTROL class constrained the PROJECT class and its subclasses and the PROJECT class was controlled by the CONTROL class. Composition represented how the CREW class consisted of the LABOR and EQUIPMENT classes since the LABOR and EQUIPMENT classes were a subset of the CREW class. Table 5. shows those slots for relations between classes. Table 6. shows the summary of the CONTROL classes applicable to each process of the scheduling scenario.

Table 5. Slots for Relationship between Classes

\begin{tabular}{|c|c|c|c|}
\hline $\begin{array}{l}\text { Class } \\
\text { (Domain) }\end{array}$ & Slot & $\begin{array}{l}\text { Related class } \\
\text { (Range) }\end{array}$ & $\begin{array}{l}\text { Inverse } \\
\text { Slot }\end{array}$ \\
\hline Process & Use & Input & Is used by \\
\hline Process & $\begin{array}{l}\text { Is controlled } \\
\text { by }\end{array}$ & Control & Constrains \\
\hline Process & Contains & Work item & Is part of \\
\hline Work item & Contains & Activity & Is part of \\
\hline Crew & Composition & $\begin{array}{l}\text { Labor and } \\
\text { Equipment }\end{array}$ & Null \\
\hline
\end{tabular}

Table 6. Control Class in Scenario

\begin{tabular}{ll}
\hline \multicolumn{1}{c}{ Scenario } & \multicolumn{1}{c}{$\begin{array}{c}\text { Control Class (including } \\
\text { subclasses if available) }\end{array}$} \\
\hline $\begin{array}{l}\text { 1. Project breakdown into } \\
\text { work item }\end{array}$ & Contract \\
$\begin{array}{l}\text { 2. Work item breakdown } \\
\text { into activity }\end{array}$ & Historical data/Dependency \\
$\begin{array}{l}\text { 3. Activity ordering } \\
\text { 4. Resource allocation }\end{array}$ & $\begin{array}{l}\text { Dependency } \\
\text { 5. Activity duration } \\
\text { 6. Cost calculation }\end{array}$ \\
7. Scheduling output & Productivity rate/Calculation \\
\hline
\end{tabular}

\section{Conclusion}

In order to formalize the construction scheduling process from the subcontractor's standpoint, an inductive approach was used. Accomplishing this formalization needed two phases of effort: The first phase refined a case study with a roofing subcontractor and provided the foundation for the KRM. In the second phase, the data gathered were combined with general concepts of construction scheduling aiming at developing a synthetic firm-specific KRM, utilizing the methods of data representation such as the IDEFO Process Model. The KRM represented the definitions of concepts and the relationships between concepts in Protégé 2002.

Even though the subcontractor's scheduling process varied, the KRM design provided general insights into the process, and other subcontractors' processes could also be retrieved through the design, by making a comparison with the scenario. The KRM developed in the research made an assumption of similarity among construction subcontractors in terms of project processes and information usage. The tool of the KRM may be further developed to accommodate processes that follow decisions in the scheduling process because those decisions were influenced by multiple factors.

\section{Acknowledgment}

This research was supported by Basic Science Research Program through the National Research Foundation of Korea (NRF) funded by the Ministry of Education, Science and Technology (grant number: 2012-R1A1A1014758). 